\title{
CAPÍTULO 23: EFEITOS DO USO DO CAMPO MAGNÉTICO NA ATIVIDADE ENZIMÁTICA IN VITRO: REVISÃO INTEGRATIVA
}

\author{
CHAPTER 23: EFFECTS OF THE USE OF THE MAGNETIC FIELD IN \\ ENZYMATIC ACTIVITY IN VITRO: INTEGRATIVE REVIEW
}

\author{
Emeson Farias Araujo Santos ${ }^{1}$; Rodrigo Lira de Oliveira ${ }^{2}$; Tatiana Souza Porto ${ }^{3}$; Camila Souza Porto ${ }^{4}$
}

\begin{abstract}
Resumo
Entre diversos tipos de biomoléculas, as enzimas possuem uma sensibilidade magnética ao ponto de modificar sua estrutura tridimensional. Essa modificação contribui no processo do encaixe-induzido da enzima ao substrato, e dependendo do tipo da classe enzimática e da intensidade do fluxo magnético pode haver uma diminuição ou aumento na atividade catalítica. Devido a isso, esse trabalho teve por objetivo sintetizar os trabalhos já publicados por meio de uma busca sistemática da literatura a fim de compreender quais enzimas já foram expostas ao tratamento do fluxo magnético para avaliar o efeito na atividade catalítica. Tratase de uma revisão integrativa. A busca foi realizada nas bases eletrônicas de dados Medline, Web of Science e Google scholar. Os critérios de elegibilidade foram artigos originais in vitro que utilizaram o campo magnético na atividade enzimática, publicada entre os anos de 2015 a 2020. Os artigos foram avaliados de acordo com os princípios de Bardín com análise do documento. Dos 69 artigos rastreados, participaram da revisão integrativa 08 artigos. Foi verificado artigos com resultados negativos e positivos. No entanto, a maioria teve efeito positivo, com aumento na atividade enzimática. Conclui-se que o campo magnético é uma alternativa para potencializar a atividade da enzima. Implicando em melhorar as condições reacionais na obtenção da enzima mais competitiva no setor industrial.
\end{abstract}

Palavras-Chave: Fluxo magnético, Catálise enzimática, Magnetismo.

\begin{abstract}
Among several types of biomolecules, enzymes have a magnetic sensitivity to the point of modifying their three-dimensional structure. This modification contributes to the enzymeinduced fitting process to the substrate, and depending on the type of enzyme class and the intensity of the magnetic flux, there may be a decrease or increase in catalytic activity. Because of this, this work aimed to synthesize the works already published through a systematic search of the literature in order to understand which enzymes have already been exposed to the treatment of magnetic flux to evaluate the effect on catalytic activity. This is an integrative review. The search was performed in the electronic databases Medline, Web of Science and Google scholar. The eligibility criteria were original in vitro articles that used the magnetic field for enzyme activity, published between the years 2015 to 2020. The articles were evaluated according to the Bardín principles with analysis of the document. Of the 69 articles screened, 08 articles participated in the integrative review. Articles with negative and positive results were verified. However, most had a positive effect, with an increase in enzyme activity. It is concluded that the magnetic field is an alternative to enhance the activity of the enzyme. Implying in improving the reaction conditions in obtaining the most competitive enzyme in the industrial sector.

\footnotetext{
${ }^{1}$ Licenciatura em Ciências Biológicas, Universidade Federal de Alagoas, emeson.araujo.santos@ @mail.com ${ }^{2}$ Doutor em Biotecnologia Industrial, Universidade Federal Rural de Pernambuco, rodrigolira1@ outlook.com ${ }^{3}$ Doutora em Tecnologia Bioquímico-Farmacêutica, Universidade Federal Rural de Pernambuco, mailto:portots@yahoo.com.br

${ }^{4}$ Doutora em Biotecnologia Industrial, Universidade Federal de Alagoas, camila.porto@ penedo.ufal.br
} 
Keywords: Magnetic flux, Enzymatic catalysis, Magnetism.

\section{Introdução}

Para a produção de alimentos capazes de suprir as necessidades humanas, a agroindústria encontra-se no desafio de aplicação de novas técnicas com maior eficácia e menor impacto no meio ambiente (DAMKE, 2019; CRUZ et al., 2020; LAVERDE; HURTADO; RODAS, 2020). No Brasil, a agroindústria é uma das atividades que tem forte impacto no produto interno bruto (PIB), contribuindo positivamente para o crescimento social e econômico do país (FURTUOSO; BARROS; GUILHOTO, 2019). Isso porque o setor agroindustrial é responsável pela geração de empregos (renda financeira) e geração de produtos alimentícios para importação e exportação (DENGO; GAZOLLA; PERONDI, 2019; DANKE, 2019).

Dentre vários setores da agroindústria há um crescimento da utilização de produtos oriundos da biotecnologia, a qual ganha destaque as enzimas comerciais (MAGALHÃES et al., 2019; RIBEIRO, 2019). As enzimas são catalizadores biológicos responsáveis por acelerar as reações químicas (NELSON; COX, 2018). No entanto, um dos grandes desafios dos pesquisadores é na produção de enzimas altamente seletiva, eficaz e consequentemente competitiva no mercado industrial (QUEIROZ; SOUSA, 2020).

Existe na literatura a reportagem de alguns fatores que afetam a atividade enzimática, tais como $\mathrm{pH}$, temperatura e a duração da atividade enzimática com o substrato (NELSON; COX, 2018). Atualmente existem estudos que comprovam o fluxo magnético como fator que altera a atividade enzimática, tanto de forma negativa quanto de forma positiva (LIU; GUO; LIU, 2015; ALEXANDER et a., 2015). No entanto, ainda falta compreender de que forma afeta a enzima e quais enzimas são afetadas, uma vez que o campo magnético pode ou não alterar a atividade das mesmas, além de reconhecer quais enzimas é afetado negativamente ou positivamente. Entender estas lacunas pode resultar na elaboração de protocolo metodológico mais eficaz na produção de enzimas mais competitiva no mercado industrial.

É constatada uma modificação na atividade enzimática, alterando a catálise da enzima, por meio da sensibilização magnética que a biomolécula sofre devido ao fluxo magnético (FRAGA, 2018). Devido a isso, pesquisadores tem investigado a partir de testes experimentais in vitro o efeito do campo magnético na atividade enzimática, no entanto é uma área não consolidada, os quais ainda procuram compreender os mecanismos biofísicos para explicar os resultados encontrados. Além de buscar compreender o porquê de haver divergências nos resultados, tanto na diminuição quanto no aumento da atividade catalítica. 
Por esta perspectiva de alteração na catálise enzimática por meio da sensibilização ao fluxo magnético, torna-se fundamental reconhecer quais as enzimas que tem potencial para aumentar sua atividade e quais são as que têm potencial para diminuir a atividade. De acordo com Fraga (2018) e Sales (2018), o campo magnético pode alterar o sítio ativo da enzima, alterar os resíduos de aminoácidos presentes na superfície da enzima ou modificar sua estrutura tridimensional, e essas mudanças vai depender de qual enzima está sendo exposta ao campo magnético.

Todo campo magnético externo pode provocar um campo magnético interno em qualquer matéria, provocando uma mudança na rotação dos spins dos átomos constituintes do corpo (matéria) afetado pelo campo magnético externo. No entanto, quando o campo magnético externo é retirado, o campo magnético interno é desfeito (BAUER; WESTFALL; DIAS, 2012). Estudos recentes apontam que é enzima é sensível ao campo magnético externo, modificando sua estrutura tridimensional, através da mudança das ligações peptídicas, e atividade catalítica. Porém, pouco se sabe o nível de sensibilidade de cada enzima e até que ponto determinada enzima pode permanecer com sua atividade catalítica após a exposição do campo magnético, cuja retirada do campo magnético externo desfaz o campo magnético interno na enzima, voltando a sua estrutura e atividade natural.

Dessa forma, a revisão integrativa é uma ferramenta importante que, diferente da revisão narrativa, explora áreas de estudos mais gerais, localizando pontos focais por meio de uma visão mais geral do campo estudo. Demonstrando, por meio de uma busca sistemática da literatura disponível nas bases de dados, os trabalhos recentes, os países com maior interesse na área, quais são os principais grupos de estudos e pesquisadores da área, além de integrar e sintetizar os resultados principais dos trabalhos originais.

Nessa situação, para compreender quais enzimas foram afetadas pelo campo magnético, bem como quais sustentações metodológicas e justificativas foram abordadas nos estudos experimentais, foi conduzida uma revisão integrativa sistematicamente para reunir as evidências disponíveis sobre o uso do campo magnético na atividade enzimática em testes laboratoriais in vitro.

\section{Desenvolvimento}

O presente trabalho consiste em uma pesquisa bibliográfica baseada nos princípios norteadores de Mendes, Silveira e Galvão (2008) por meio de uma revisão integrativa, sendoos: Identificação da problemática, com uma busca sistemática da literatura compreendendo as lacunas do tema e o propósito da pesquisa de revisão; uma busca da literatura sistematizando 
etapas para seleção dos estudos, com padronização de palavras-chave, as bases de dados que foram usadas para selecionar os artigos primários e os critérios de inclusão e exclusão dos trabalhos encontrados nas bases de dados; avaliação dos trabalhos selecionados para verificar se realmente eram legíveis para coleta de dados; e por fim, análise dos dados.

A utilização do campo magnético como ferramenta metodológica para alterar a atividade enzimática in vitro é um campo de estudo recente, com poucos estudos realizados, no qual poucas enzimas foram expostas ao campo magnético. Consequentemente, ainda não existe um padrão metodológico para avaliar os efeitos do fluxo magnético, nem uma discussão teórica forte que justifique tais efeitos, o que ocasionar em cada grupo de pesquisar formular sua própria metodologia, o que dificulta a realização de meta-análise nas revisões sistemáticas. Devido a isto, esta pesquisa foi de natureza quanti-qualitativa, uma vez esta pesquisa teve como objetivos específicos realizar um levantamento sistemático dos trabalhos referentes aos resultados do efeito do campo magnético em atividades enzimáticas in vitro, bem como analisar o discurso das teorias fundamentadas nas justificativas e metodologias utilizadas nestes trabalhos.

\subsection{Identificação do problema}

Para nortear a realização da pesquisa de revisão formulou-se a seguinte questão: Quais os efeitos do uso do campo magnético em atividades enzimáticas em testes laboratoriais in vitro? A busca dos estudos ocorreu entre o período de dezembro de 2019 a junho de 2020. Para os critérios de inclusão foram padronizados a seleção de estudos publicados nos últimos seis anos, em específico os trabalhos publicados entre os anos de 2015 a 2020, nos idiomas inglês, espanhol e português, que apresentaram em sua discussão o efeito do campo magnético em atividades enzimáticas in vitro. Foram excluídos artigos de revisão, pesquisa laboratorial in vivo, duplicatas e estudos publicados em anos anteriores a 2015.

\subsection{Busca da literatura}

Foi realizada a busca eletrônica dos trabalhos indexados nas bases de dados gerais: Medline (via Pubmed) e Web of Science. Para a busca da literatura cinzenta foram utilizados: Google scholar. A realização da busca ocorreu por meio de dois pesquisadores de forma independente, com auxílio de um terceiro pesquisador quando houve discordância entre os dois pesquisadores. As palavras-chave utilizadas foram padronizadas por meio descritores, pesquisada em português e inglês: "Campo magnético" e "atividade enzimática" ("Magnetic field" and "enzymatic activity") ("Campo magnético" y "actividad enzimática"); "Campo 
magnético e aumento na atividade enzimática" ("Magnetic field" and "increased enzyme activity") ("Campo magnético y mayor actividad enzimática"); "Campo magnético" e “diminuição na atividade enzimática" ("Magnetic field" and "decrease in enzyme activity") ("Campo magnético" y "disminución de la actividad enzimática"); "Exposição do campo magnético" e "atividade enzimática" ("Magnetic field exposure" and "enzyme activity") ("Exposición al campo magnético" y "actividad enzimática"); "Exposição do Campo magnético" e "modificação tridimensional da enzima" ("Magnetic field exposure" and "threedimensional modification of the enzyme") ("Exposición al campo magnético" y "modificación tridimensional de la enzima"); "Exposição do campo magnético" e "inativação do sítio ativo enzimático" ("Magnetic field exposure" and "inactivation of the enzymatic active site") ("Exposición al campo magnético "e“ inactivación del sitio activo enzimático ”); e "Exposição do campo magnético" e "estrutura tridimensional da enzima" ("Exposure of the magnetic field" and "three-dimensional structure of the enzyme") ("Exposición al campo magnético" y "estructura tridimensional de la enzima").

A seleção dos estudos ocorreu em duas etapas. Primeiro uma avaliação do título e resumo, de forma independente pelos dois pesquisadores, com auxílio da plataforma digital Rayyan QCRI. Após a seleção dos estudos incluídos por meio do título e resumo houve uma leitura integral dos textos utilizando o diagrama PRISMA (Figura 1).

\subsection{Coleta e análise dos dados}

Os dados foram extraídos conforme consta no protocolo dos estudos primários selecionados: autor, ano, país, pico (População, intervenção, comparador e desfecho) e resultado. Para a análise qualitativa dos estudos foram adotados os princípios metodológicos de Bardin (2008), com a análise do conteúdo (Figura 2).

A primeira fase consistiu em organizar os conteúdos de acordo com as informações que se pretendia analisar, como exemplo a busca sistemática dos artigos primários que discutiam o uso do campo magnético em atividade enzimática in vitro. A segunda etapa foi codificar as informações por meio de registro de unidade (procedimentos metodológicos para o uso do campo magnético, intensidade do fluxo magnético utilizado, autores, ano de publicação, país onde a pesquisa foi realizada, tipo de enzima utilizada, resultado da pesquisa, fundamentação e justificativa teórica da pesquisa) e registro de conceito (introdução, metodologia, resultados, discussão e conclusão). E por fim, a terceira etapa foi uma abordagem de sintetizar as informações categoricamente de acordo com as unidades de 
registro, apresentado os dados por autor, ano de publicação, país, enzima, metodologia utilizada, resultado e justificativa.

Figura 1. Fluxograma para realização da revisão sistemática integrativa PRISMA.

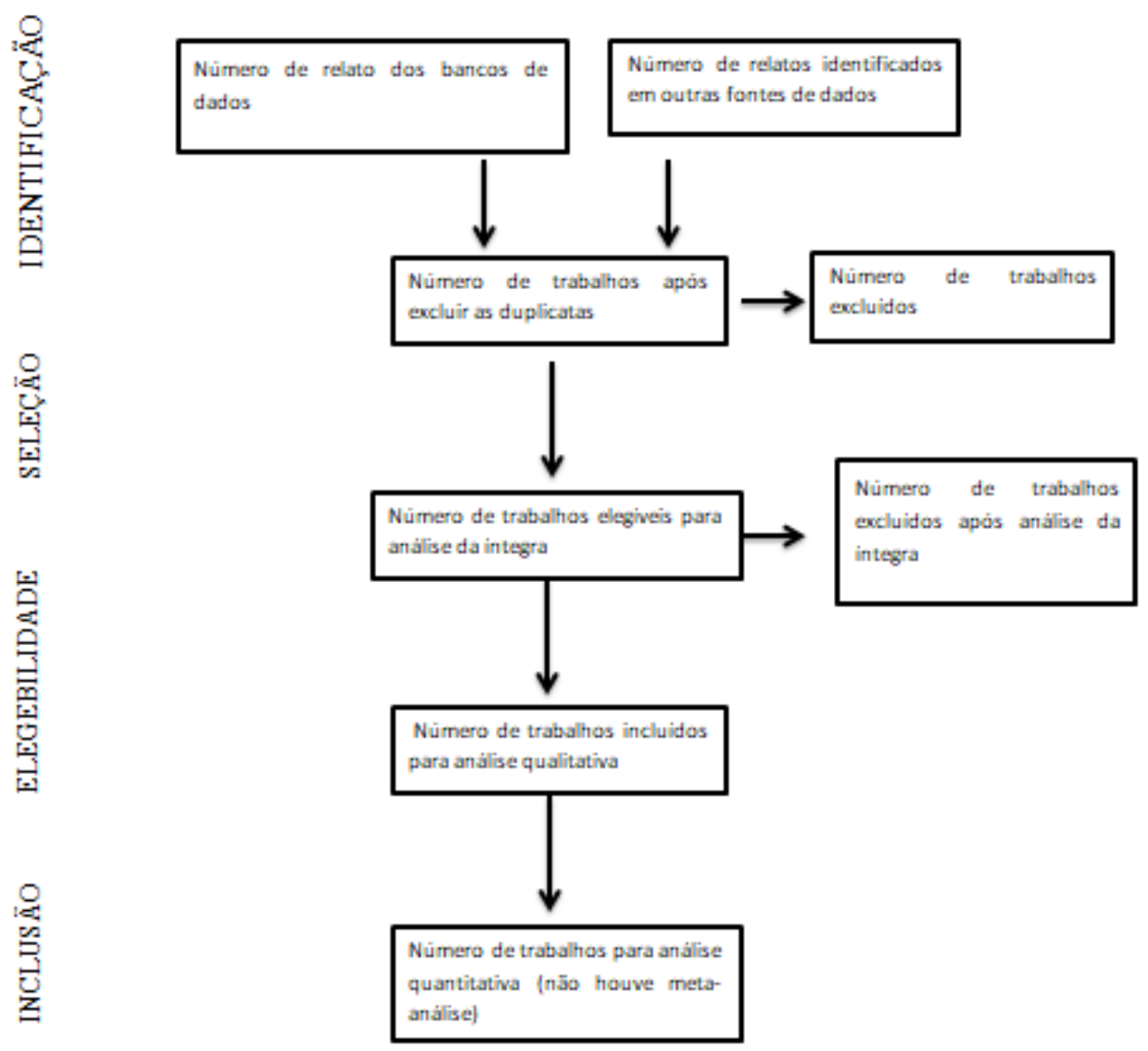

Fonte: Crochane (2015)

Figura 2. Etapas para análise do conteúdo de acordo com os princípios norteadores de Bardin (2014).

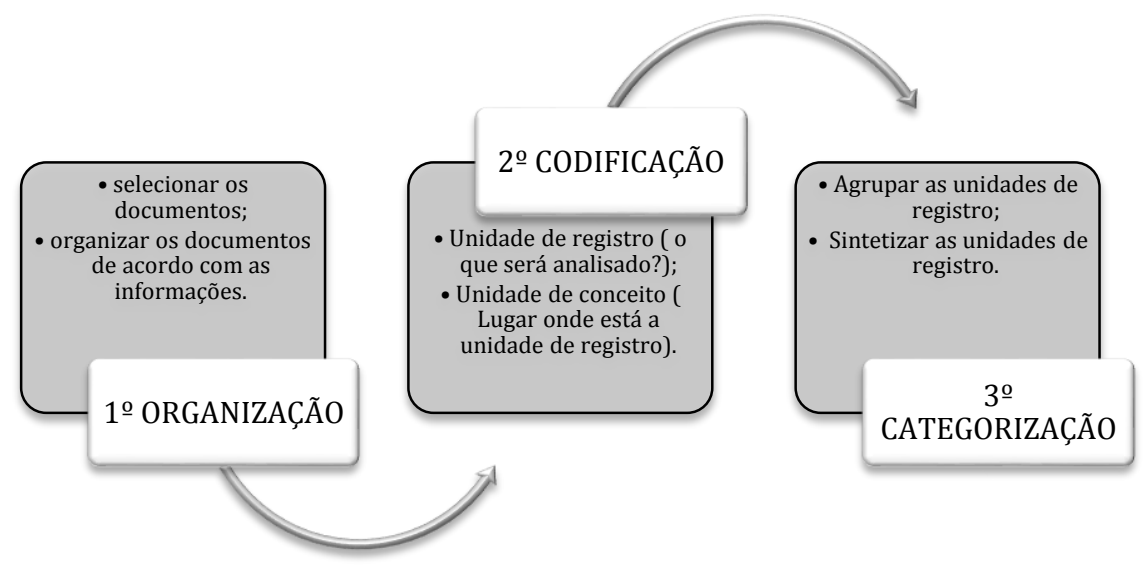

Fonte: Bardin (2014) 


\section{Discussão}

Diversos grupos de pesquisas têm investido na análise do efeito do campo magnético em sistemas biológicos, utilizando testes in vitro e in vivo, como exemplo: a importância do campo para crescimento microbiano, explicado pela mudança no metabolismo dos microrganismos; nanopartículas magnéticas como suporte para imobilização de enzimas e análise do fluxo magnético na catálise enzimática (LIU; GUO; LIU, 2015; ALEXANDER et a., 2015; BORK, et al., 2015; SALES, et al. 2018; FRAGA, 2018 ). Após a busca sistemática da literatura disponível sobre os estudos primários laboratoriais in vitro com o uso do campo magnético na atividade enzimática foram rastreados 68 artigos nos quais foram incluídos 08 trabalhos para compor a revisão integrativa (Figura 3).

Figura 3. Fluxo da busca de evidência científica sobre o uso do campo magnético em atividades enzimáticas em estudos laboratoriais in vitro.

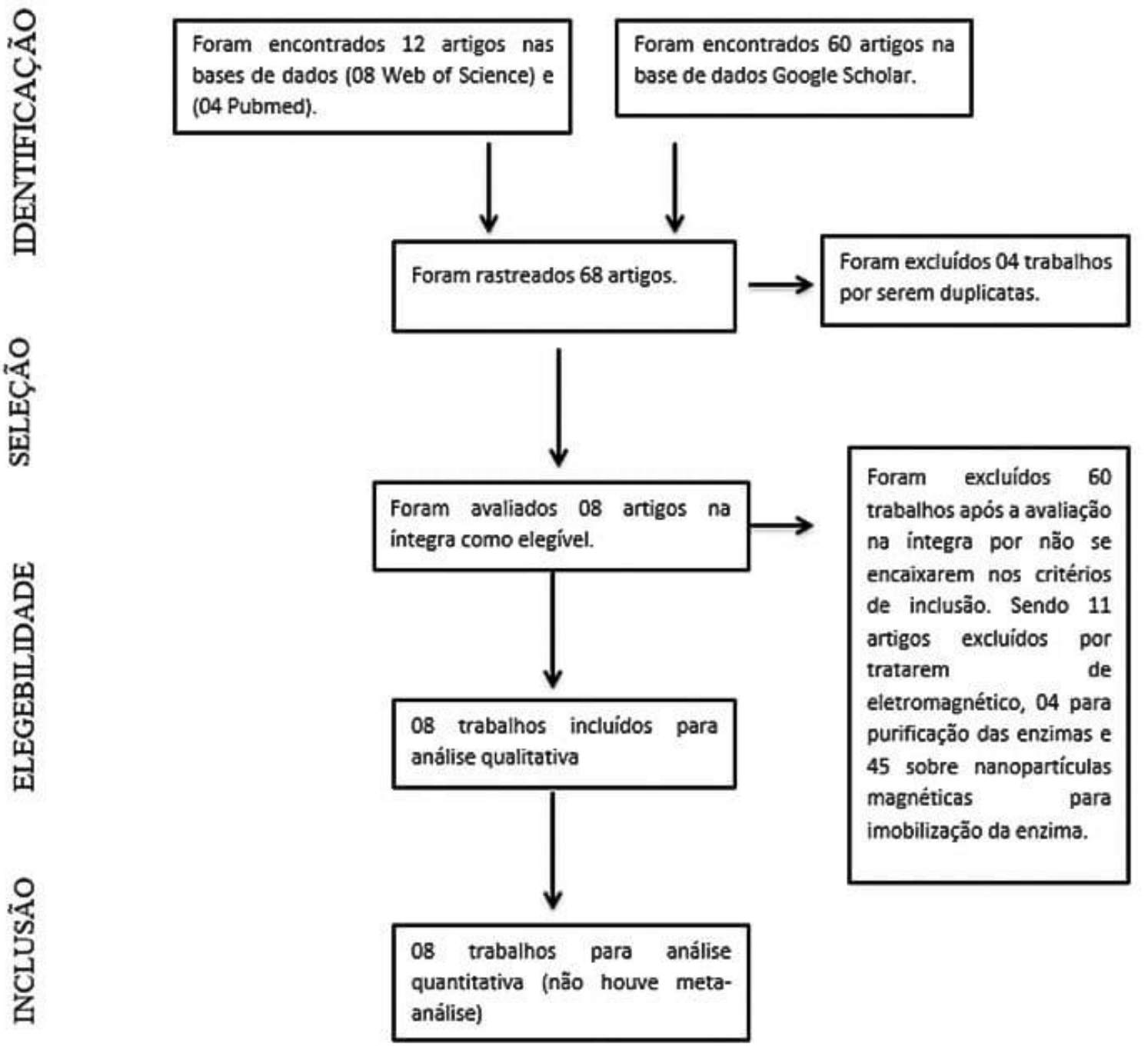


Foi observado que $66 \%$ dos trabalhos rastreados apesar de está relacionado à exposição ao campo magnético o objetivo das pesquisas não eram avaliar a influência do campo magnético da atividade enzimática, o que foi motivo de exclusão da revisão. Além dos trabalhos que utilizaram como ferramenta metodológica o eletromagnetismo. Diante disso apenas noves estudos foram incluídos (Tabela 1).

Tabela 1. Apresentação dos artigos científicos selecionados para compor a revisão integrativa por título e ano de publicação.

\begin{tabular}{|c|c|}
\hline Título & Ano \\
\hline $\begin{array}{l}\text { Enhancing the resolution of }(\mathrm{R}, \mathrm{S}) \text {-2-octanol catalyzed by magnetic crosslinked } \\
\text { lipase aggregates using an alternating magnetic field }\end{array}$ & 2015 \\
\hline $\begin{array}{l}\text { Enzyme-functionalized gold-coated magnetite nanoparticles as novel hybrid } \\
\text { nanomaterials: Synthesis, purification and control of enzyme function by low- } \\
\text { frequency magnetic field }\end{array}$ & 2015 \\
\hline $\begin{array}{l}\text { A further investigation of the effects of extremely low frequency magnetic fields } \\
\text { on alkaline phosphatase and acetylcholinesterase }\end{array}$ & 2016 \\
\hline $\begin{array}{l}\text { Characterization of the performance and catalytic activity of lysozyme from } \\
\text { chicken egg submitted to permanent magnetic field }\end{array}$ & 2017 \\
\hline $\begin{array}{l}\text { Static magnetic field effects on proteases with fibrinolytic activity produced by } \\
\text { Mucor Subtilissimus }\end{array}$ & 2017 \\
\hline $\begin{array}{l}\text { Rotating magnetic field as tool for enhancing enzymes properties - laccase case } \\
\text { study }\end{array}$ & 2018 \\
\hline $\begin{array}{l}\text { Effect of high pressure and magnetic field treatments on stability of Candida } \\
\text { antarctica lipase B (CALB) and lysozyme from chicken egg }\end{array}$ & 2018 \\
\hline $\begin{array}{l}\text { Effect of magnetic field on the Eversa }{ }^{\circledR} \text { Transform } 2.0 \text { enzyme: Enzymatic } \\
\text { activity and structural conformation }\end{array}$ & 2019 \\
\hline
\end{tabular}

\section{Fonte: Autor (2020).}

Considerando a proporção de trabalhos rastreados com os termos de busca padronizados há poucos trabalhos publicados com a temática de avaliação do campo magnético na atividade enzimática. $\mathrm{O}$ que demonstra a importância da realização de mais pesquisas na área, para expor um maior número de enzimas ao fluxo magnético e verificar os efeitos.

De acordo com os estudos rastreados desta revisão integrativa é necessário destacar que a maioria dos resultados evidenciou uma melhora na atividade enzimática devido à exposição do fluxo magnético. Dos 08 artigos incluídos neste estudo integrativo da literatura, publicado entre os anos de 2015 a 2020, apenas um artigo relatou que não houve diferença 
significativa na atividade enzimática com o uso do campo magnético, e outro estudo que notabilizou uma diminuição na atividade enzimática com a presença do campo magnético (Quadro 1).

\subsection{Países com grupos de pesquisas que estudam campo magnético na atividade enzimática.}

Foram identificados quatro países (Rússia, China e Brasil) que havia grupos de pesquisa, desenvolvido e publicado os trabalhos avaliando o campo magnético na atividade enzimática. Entre esses países, dos 08 artigos identificados 04 foram pesquisas feitas no Brasil. Com relação aos anos de publicação houve dois trabalhos publicados em 2015, um em 2016, dois em 2017, dois em 2018 e um em 2019; o que obteve maior frequência o ano de 2017.

\subsection{Procedimentos metodológicos para avaliar o campo magnético na atividade enzimática}

Os estudos rastreados e elegíveis para avaliação da revisão integrativa demonstraram diferença quanto aos parâmetros metodológicos para avaliar o efeito de campo magnético. A diferença encontra-se tanto no designer experimental quanto na intensidade e frequência do fluxo magnético.

No tratamento da lipase comercial Eversa ${ }^{\circledR}$ Transform 2.0 para o execução experimental foi utilizado um ímã permanente de neodímio borro-ferro com intensidade do fluxo magnético de 0,7 e 1,34 T. Neste trabalho foi utilizado o sistema de recirculação para analisar o efeito do campo ao tempo de exposição, com duração de 1, 2 e 4 horas. Com intuito de comprovar o efeito do campo na estrutura tridimensional da enzima este estudo procurou determinar a estrutura da enzima, a fim de verificar mudanças na estrutura secundária da proteína (FRAGA, et al., 2019).

Diferente da metodologia de Fraga (2019), o estudo de lipases sobre a exposição do campo magnético verificou e comparou tanto a intensidade bem como a frequência do fluxo magnético na atividade enzimática, adotando o uso do campo magnético alternado (PRANDO, et al., 2018). Para esse estudo só foi incluído análises estatística para corroborar com a justificativa de mudança na atividade enzimática. 
SANTOS, E.F.A. et al.

Quadro 1. Síntese categórica das principais características dos artigos incluídos neste estudo de revisão integrativa, 2020.

\begin{tabular}{|c|c|c|c|c|c|c|c|}
\hline Autor (es) & Ano & País & Enzima & Objetivo & Metodologia & Principais resultados & Conclusão \\
\hline Silkstone e Wilson & 2016 & & $\begin{array}{l}\text { Fosfatase alcalina } \\
\text { Acetilcolinesterase }\end{array}$ & $\begin{array}{l}\text { Os efeitos dos campos } \\
\text { magnéticos nas reações } \\
\text { enzimáticas }\end{array}$ & $\begin{array}{l}\text { Utilização campos } \\
\text { magnéticos, de } 100 \mu \mathrm{T} \text { a } 10 \\
\text { mT e em uma variedade de } \\
\text { frequências de campo. }\end{array}$ & $\begin{array}{c}\text { Não foi encontrado alteração } \\
\text { na atividade enzimática em } \\
\text { nenhuma frequência do } \\
\text { campo magnético. }\end{array}$ & 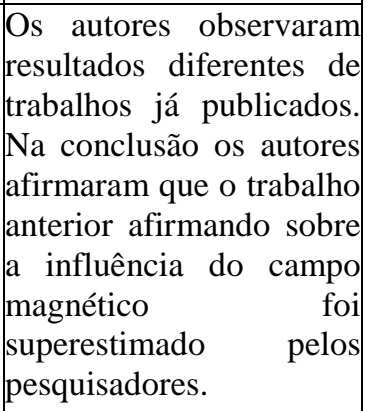 \\
\hline Liu, Guo e Liu & 2015 & China & Lipases & $\begin{array}{c}\text { Catalisar a resolução de }(\mathrm{R} \\
\text {, S ) -2-octanol sob um } \\
\text { campo magnético } \\
\text { alternado }\end{array}$ & $\begin{array}{l}\text { Utilizar o campo magnético } \\
\text { alternado para aprimorar } \\
\text { atividade da lipase. }\end{array}$ & $\begin{array}{l}\text { O campo magnético resultou } \\
\text { em aumento aparente de } \\
\text { atividade enzimática }\end{array}$ & $\begin{array}{l}\text { A frequência tem mais } \\
\text { influência do que a } \\
\text { intensidade na alteração } \\
\text { catalítica da enzima. }\end{array}$ \\
\hline Wasak et al., & 2019 & & Lacase & $\begin{array}{c}\text { o efeito da exposição do } \\
\text { campo magnético rotativo } \\
\text { (RMF) sobre o fungo e } \\
\text { atividade enzimática e } \\
\text { propriedades catalíticas da } \\
\text { lacase } \\
\end{array}$ & $\begin{array}{c}\text { Utilização do campo } \\
\text { magnético rotativo com a } \\
\text { frequência variou de } 10 \text { a } 50 \\
\text { Hz. Este trabalho não avaliou } \\
\text { a intensidade do campo } \\
\text { magnético. } \\
\end{array}$ & $\begin{array}{c}\text { Os resultados obtidos no } \\
\text { estudo revelaram que a RMF } \\
\text { pode alterar positivamente a } \\
\text { atividade de lacase }\end{array}$ & \begin{tabular}{|l|} 
A aplicação do campo \\
magnético rotativo abre \\
uma nova maneira de \\
controlar e direcionar o \\
bioprocessamento \\
baseado em enzimas. \\
\end{tabular} \\
\hline Prando et al., & 2017 & Brasil & Lisozima & $\begin{array}{c}\text { Avaliar os efeitos de um } \\
\text { campo magnético } \\
\text { permanente e as condições } \\
\text { operacionais atividade } \\
\text { catalítica, estrutura } \\
\text { enzimática secundária e } \\
\text { terciária, e tamanho de } \\
\text { partícula da lisozima da } \\
\text { clara do ovo. }\end{array}$ & $\begin{array}{c}\text { Aplicação do campo } \\
\text { magnético com densidade de } \\
0,71 \mathrm{~T} \text { e } 1,34 \mathrm{~T} \text {. }\end{array}$ & $\begin{array}{c}\text { A densidade de fluxo } \\
\text { magnético e } \mathrm{pH} \text { apresentaram } \\
\text { efeitos positivos } \\
\text { significativos }(\mathrm{p}<0,1) \text { na } \\
\text { atividade enzimática. }\end{array}$ & $\begin{array}{l}\text { Alteração no sítio ativo } \\
\text { da enzima. }\end{array}$ \\
\hline Prando et al., & 2018 & Brasil & $\begin{array}{c}\text { Lipase de Candida } \\
\text { antarctica e } \\
\text { Lisozima do ovo da } \\
\text { galinha }\end{array}$ & $\begin{array}{l}\text { Tratar enzimas com alta } \\
\text { pressão ou campo } \\
\text { magnético e avaliar seu } \\
\text { armazenamento e } \\
\text { estabilidade após o } \\
\text { tratamento. }\end{array}$ & $\begin{array}{l}\text { Testes com campo magnético } \\
\text { estático gerando um campo } \\
\text { magnético de fluxo de } 0,7 \mathrm{~T} \mathrm{e} \\
1,34 \mathrm{~T} \text {. }\end{array}$ & $\begin{array}{c}\text { A aplicação de um campo } \\
\text { magnético de } 1,34 \mathrm{~T} \\
\text { aumentou a atividade da } \\
\text { lisozima em cerca de } 55 \%, \\
\text { enquanto um tratamento com } \\
0,7 \mathrm{~T} \text { aumentou } 80 \% \text { da } \\
\text { atividade da lipase de } C . \\
\text { antarctica. }\end{array}$ & \\
\hline
\end{tabular}




\begin{tabular}{|c|c|c|c|c|c|c|c|}
\hline Autor (es) & Ano & País & Enzima & Objetivo & Metodologia & Principais resultados & Conclusão \\
\hline Fraga et al., & 2018 & Brasil & $\begin{array}{c}\text { Eversa }{ }^{\circledR} \\
\text { Transform } 2.0\end{array}$ & $\begin{array}{l}\text { Investigar a estrutura } \\
\text { tridimensional da enzima, } \\
\text { bem como a atividade sob } \\
\text { exposição do campo } \\
\text { magnético. }\end{array}$ & $\begin{array}{c}\text { Investir por técnicas } \\
\text { espectroscópicas e de } \\
\text { espectrometria de massa após } \\
\text { exposição em densidade de } \\
\text { fluxo magnético atual }(0,7 \text { e } \\
1,34 \mathrm{~T}) \text { no modo de } \\
\text { recirculação }(1,2 \text { e } 4 \mathrm{~h}) .\end{array}$ & $\begin{array}{l}\text { Notou-se mudança na } \\
\text { conformação estrutural da } \\
\text { enzima com exposição do } \\
\text { campo magnético, além de } \\
\text { melhorado sua atividade. }\end{array}$ & $\begin{array}{lrr}\text { A aplicação } & \text { de } & \text { campos } \\
\text { magnéticos } & \text { como } & \text { pré- } \\
\text { tratamento } & \text { enzimático } \\
\text { mostrou-se } & \text { uma } & \text { técnica } \\
\text { promissora } & \text { e } & \text { uma } \\
\text { alternativa } & \text { viável } & \text { para } \\
\text { aumentar a } & \text { atividade } \\
\text { enzimática, uma vez que } \\
\text { é uma opção de baixo } \\
\text { custo, ecológica e } & \text { de } \\
\text { fácil processo } & \text { de } \\
\text { regeneração. } & \\
\end{array}$ \\
\hline Albuquerque et al., & 2017 & Brasil & $\begin{array}{l}\text { Proteases } \\
\text { fibrinolíticas }\end{array}$ & $\begin{array}{c}\text { Efeitos do campo } \\
\text { magnético estático em } \\
\text { proteases fibrinolíticas. }\end{array}$ & \begin{tabular}{|} 
Foram utilizados para realizar \\
ensaios em campos \\
ligeiramente heterogêneos: \\
um SMF vertical variado \\
(para testes em microtubos, de \\
0,100 a $0,170 \mathrm{~T}$ ) e um SMF \\
horizontal variado (para testes \\
em placas de Petri, 0,01 a \\
$0,122 \mathrm{~T}$ ), gerado por dois ímãs \\
permanentes (liga $\mathrm{NdFeB}$ )
\end{tabular} & $\begin{array}{c}\text { Os resultados } \\
\text { mostraramdiferenças } \\
\text { significativas }(p<0,05) \text { nos } \\
\text { ensaios de fibrinólise estática } \\
\text { após } 24 \text { horas de exposição. }\end{array}$ & $\begin{array}{|lr|}\text { Esses resultados sugerem } \\
\text { uma resposta } \\
\text { demonômeros de fibrina } \\
\text { para o SMF como uma } \\
\text { possível causa dos } \\
\text { efeitos observados }\end{array}$ \\
\hline Majougaa et al., & 2015 & Rússia & Quimotripsina & \begin{tabular}{|c} 
Nanopartículas de \\
magnetita revestidas a \\
ouro com funcionalidade \\
enzimática como \\
novonanomateriais \\
híbridos: síntese, \\
purificação e controle de \\
enzimas função por campo \\
magnético de baixa \\
frequência
\end{tabular} & \begin{tabular}{|c} 
A amplitude do campo \\
magnético pode variar na \\
faixa de mT a $250 \mathrm{mT}$. \\
Os experimentos foram \\
realizados na frequência de 50 \\
Hz e intensidade do campo \\
magnético variou de 15 a 220 \\
$\mathrm{kA} / \mathrm{m}$.
\end{tabular} & $\begin{array}{l}\text { O efeito do campo magnético } \\
\text { CA de baixa frequência na } \\
\text { atividade catalítica do } \\
\text { quimiotripsina imobilizada } \\
\text { foi positiva. }\end{array}$ & $\begin{array}{l}\text { A atividade enzimática } \\
\text { diminui com a exposição } \\
\text { dos NPs ao campo } \\
\text { magnético }\end{array}$ \\
\hline
\end{tabular}


Estes exemplos de metodologias demonstra a ausência de uma padronização de protocolo, uma vez que cada grupo de pesquisa elabora seu próprio procedimento experimental. Por outro lado, essa variação de procedimento metodológico reforça a riqueza de propostas de protocolos que podem ser usado para verificar efeito do campo magnético na atividade enzimática.

\subsection{Tipos de enzimas submetidas ao tratamento sobre o efeito do campo magnético na atividade enzimática}

Notou-se a exposição de 11 enzimas ao campo magnético, sendo-as: Fosfatase alcalina; acetilcolinesterase; lipases reticuladas; lacase; lisozima; lipase de C. antarctica; lisozima do ovo da galinha; lipase comercial Eversa ${ }^{\circledR}$ Transform 2.0; proteases fibrinolíticas; $\alpha$-amilase; e quimiotripsina.

Tabela 2. Enzimas expostas ao fluxo magnético versus efeito na atividade enzimática.

\begin{tabular}{|c|c|}
\hline Enzimas & Desfecho \\
\hline Fosfatase alcalina & $\begin{array}{l}\text { Não houve diferença na atividade enzimática com o } \\
\text { campo magnético, independente da intensidade e } \\
\text { frequência. }\end{array}$ \\
\hline Acetilcolinesterase & $\begin{array}{l}\text { Não houve diferença na atividade enzimática com o } \\
\text { campo magnético, independente da intensidade e } \\
\text { frequência. }\end{array}$ \\
\hline Lipases reticuladas & $\begin{array}{l}\text { Houve aumento significativo na atividade enzimática, } \\
\text { porém foi notado que a frequência tem potencial maior } \\
\text { que a intensidade de alterar a atividade enzimática. }\end{array}$ \\
\hline Lisozima & Efeito positivo na atividade enzimática. \\
\hline Lacase & Houve alteração positiva na atividade da enzima. \\
\hline Lipase de C. antarctica & $\begin{array}{l}\text { Efeito positivo na atividade enzimática (aumento de } \\
80 \% \text { ). }\end{array}$ \\
\hline Lisozima do ovo da galinha & Efeito positivo na atividade (aumento de $55 \%$ ) \\
\hline Lipase comercial Eversa ${ }^{\circledR}$ Transform 2.0 & Efeito positivo na atividade da enzima. \\
\hline Proteases fibrinolíticas & Efeito positivo na atividade enzimática. \\
\hline Quimotripsina & $\begin{array}{l}\text { Efeito negativo na atividade enzimática, notando que } \\
\text { quanto maior a exposição da enzima com o campo } \\
\text { magnético, menor era atividade. }\end{array}$ \\
\hline
\end{tabular}

Fonte: Autor (2020).

Foi possível destacar que a partir dos resultados destes trabalhos rastreados a frequência tem potencial maior que a intensidade de acarretar mudança na atividade enzimática. Além de que dos noves trabalhos apenas um pode verificar tanto a mudança na 
atividade, bem como a alteração tridimensional da enzima, corroborando com a fundamentação teórica de que o campo magnético pode modificar a orientação dos spins nos átomos das moléculas dos aminoácidos, o que altera os tipos de ligações peptídicas, modificando a estrutura da enzima.

\subsection{Fundamentação teórica sobre o efeito do campo magnético na atividade enzimática}

Quanto ao referencial teórico, os autores tiveram a mesma linha de pensamento para justificar o efeito do campo magnético na atividade enzimática. Todos os autores classificaram as enzimas como moléculas diamagnéticas, uma forma de atração e repulsão da macromolécula (FLORÊNCIO; MONSANTO; MERGULHÃO, 2017). E que o fluxo magnético externo pode acarretar momentos dipolo magnéticos interno na enzima, modificando integralmente ou parcialmente a estrutura da enzima, o que inclui o sítio ativo e os resíduos de aminoácidos presentes nas extremidades da molécula.

Esse argumento é compreendido pelo fato que toda matéria é susceptível a momento dipolo magnético (BAUER; WESTFALL; DIAS, 2012). No entanto esses momentos são pontuais, ocorrendo apenas quando há um estímulo externo, no caso um campo magnético externo. Com isso, sabe-se que quando a enzima é retirada da exposição do fluxo magnético, sua atividade e estrutura voltam ao normal. Porém há poucos trabalhos relatando até quanto tempo a enzima consegue permanecer com a atividade alterada após e exposição.

Nesta revisão pode-se notar que os autores justificam a mudança na atividade devido à alteração na conformação tridimensional devido à mudança nas ligações peptídicas, no entanto apenas um artigo incluiu em sua metodologia um procedimento que verifica se houve mudanças na conformação. Isso demonstra as limitações dos demais trabalhos em comprovar a mudança na estrutura da enzima.

Essa modificação na estrutura tridimensional da enzima é decorrente de um efeito em cascata, no qual o campo magnético externo induz um campo magnético interno, modificando as orientações espaciais dos spins dos átomos constituintes do biocatalizador. A mudança de orientação desses spins modifica as ligações entre os átomos, modificando a estrutura secundária da molécula, o que irá modificar a estrutura tridimensional. No entanto, é importante ressaltar que o nível dessas modificações dependerá do quão sensível é a enzima ao campo magnético. Logo, esse processo de mudança poderá influenciar na catálise, e dependendo da mudança poderá ser positivamente ou negativamente. 


\subsection{Influência do campo magnético na teoria chave-fechadura versus encaixe-induzido}

A teoria chave-fechadura conceituava a enzima como uma macromolécula muito específica, com o sítio ativo inflexível (NELSON; COX, 2018). No entanto, ao decorrer dos anos, pesquisadores descobriram que apesar da enzima ser considerada específica para cada tipo de substrato, o seu sítio ativo ou os resíduos de aminoácidos eram flexíveis (ALMEIDA; KIILL, 2019). Ou seja, no momento da catálise enzimática, o sítio ativo ou os resíduos de aminoácidos presentes nas periferias externa da estrutura enzimática atua de forma flexível por meio de uma indução até se encaixar com o determinado substrato.

A influência do campo magnético no processo do encaixe-induzido pode ser observada na alteração do sítio ativo ou a orientação espacial dos resíduos de aminoácido, presente na superfície da estrutura enzimática, quando ligada ao substrato. Isso pode ser exemplificado nos estudos da exposição do campo magnético na lacase. Ao analisar o efeito da frequência magnética na cinética enzimática da lacase, Wasak et al. (2019) observaram que o $K_{m}$ aumentou e $0,021 \mathrm{mmol}$ para $0,056 \mathrm{mmol}$ com a frequência de $30 \mathrm{~Hz}$. Porém, com a exposição de outras frequências não notaram mudança na cinética.

Em teoria, trata-se de que um campo magnético externo induz um campo magnético interno na enzima provocando uma alteração na conformação tridimensional devido às ligações peptídicas. Na prática, a exposição do fluxo magnético na enzima altera a estrutura.

No entanto, dependendo do tipo de enzima a alteração pode ser um efeito positivo favorecendo um melhor encaixe ao substrato ou um efeito negativo com uma estrutura que dificulte o encaixe. Exemplo disso é o estudo de quimiotripsina que com a exposição ao campo magnético houve uma diminuição em sua atividade catalítica, que provavelmente foi devido uma alteração em sua estrutura no qual dificultou o encaixe ao substrato (ALEXANDER et a., 2015).

Por fim, é importante compreender que a mudança na estrutura da enzima vai depender do quão sensível é essa macromolécula. Pois, há enzimas que podem ter um nível muito baixo de sensibilização ao ponto de não haver efeito do fluxo magnético em sua estrutura e atividade catalítica. Isso é exemplificado pelo estudo com as enzimas fosfatase alcalina e acetilcolinesterase ao tratamento do campo magnético em diferentes níveis de intensidade ao fluxo magnético, no qual não houve mudança estatisticamente significativa na atividade catalítica das duas enzimas (SILKSTONE; WILSON, 2016). 


\section{Considerações Finais}

Durante os últimos seis anos, entre 2015 a 2020, houve a publicação de nove artigos que avaliaram o efeito do campo magnético na atividade catalítica da enzima. Entre esses estudos, a maioria resultou em um efeito positivo, com aumento na atividade enzimática. É uma área de pesquisa recente no qual não existe um padrão de protocolo para os experimentos, o que resulta em cada grupo de pesquisa elaborar seu próprio protocolo. Além disso, notaram-se algumas limitações nos artigos, exemplo disso foi à falta de mais análises que provassem a mudança na estrutura enzimática.

Esta revisão permitiu compreender que o campo magnético é uma ferramenta metodológica com potencial para melhorar a catálise enzimática, dependendo do quão sensível é a enzima ao fluxo magnético. A partir disso surge a demanda de investimento em pesquisas que possam avaliar o efeito do campo magnético em mais enzimas. Por fim, a aplicação do campo magnético é uma boa alternativa para gerar e potencializar um biocatalizador com mais competitividade no mercado industrial.

\section{Referências}

ALBUQUERQUE, W.; NASCIMENTO, T.; BRANDÃO- COSTA, R.; FERNANDES, T.; PORTO, A. Static magnetic field effects on proteases with fibrinolytic activity produced by Mucor subtilissimus. Bioelectromagnetics, 38(2), 109-120, 2017.

BARDIN, L. Análise de conteúdo. Lisboa (Portugal): Edições 70, 2008.

BAUER, W.; WESTFALL, G. D.; DIAS, H. Física para Universitários-Eletricidade e Magnetismo. AMGH Editora, 2012.

BORK, J.; HENRIQUES, R.; WEINSBERGER, G.; FURIGO JR, A. Síntese e imobilização da lipase de Rhizomucor miehei em nanopartículas magnéticas modificadas com moléculas de lauril sulfato. In: Anais do XX Congresso Brasileiro de Engenharia Química. São Paulo: Editora Edgard Blücher. 2015.

CRUZ, F. T. Agricultura familiar, processamento de alimentos e avanços e retrocessos na regulamentação de alimentos tradicionais e artesanais. Revista de Economia e Sociologia Rural, 58.2, 2020.

DAMKE, L. I.; GOMES, C. M.; GODOY, T. P.; ROSA, L. A. B.; PATIAS, T. Z. Políticas públicas para agroindústrias familiares e o desenvolvimento regional. Estudos Sociedade e Agricultura, 27 Edição 2, p. 418-439, 2019. 
DENGO, M. B.; GAZOLLA, M.; PERONDI, M. A. Novidades territorializadas das agroindústrias familiares do Sudoeste do Paraná. Seminário Internacional sobre Desenvolvimento Regional, 2019.

FLORÊNCIO, O.; MONSANTO, S. A.; MERGULHÃO, S. Fundamentos de Física 2. 2017. FRAGA, F. C. Influência de campo magnético na conformação estrutural e atividade enzimática de hidrolases. / Fernanda Cristina Fraga; orientadora, Débora de Oliveira, coorientadora, Alexsandra Valério, coorientador, Marco Di Luccio, 2018. Dissertação (mestrado) - Universidade Federal de Santa Catarina, Centro Tecnológico, Programa de PósGraduação em Engenharia Química, Florianópolis, 2018.

FRAGA, Fernanda Cristina, et al. Effect of magnetic field on the Eversa ${ }^{\circledR}$ Transform 2.0 enzyme: Enzymatic activity and structural conformation. International journal of biological macromolecules, 122: 653-658, 2019.

FURTUOSO, M. C. O.; BARROS, G. S. A. C.; GUILHOTO, J. J. M. O produto interno bruto do complexo agroindustrial brasileiro. Revista de Economia e Sociologia Rural, 36.3: 9-32, 2019.

HAGHI, M., et al. Efeito do campo magnético de baixa densidade gerado por Helmholtz Coil na atividade da $\alpha$-amilase e sensibilidade antibiótica de $B$. cereus. International Journal of Advanced Research in Science, Engineering and Technology, 4, 7, 2017.

LIU, Y.; GUO, C.; LIU, Chun-Zhao. Enhancing the resolution of (R, S)-2-octanol catalyzed by magnetic cross-linked lipase aggregates using an alternating magnetic field. Chemical Engineering Journal, 280: 36-40, 2015.

LIU, Y.; GUO, C.; LIU, Chun-Zhao. Enhancing the resolution of (R, S)-2-octanol catalyzed by magnetic cross-linked lipase aggregates using an alternating magnetic field. Chemical Engineering Journal, 280: 36-40. 2015.

MAGALHÃES, N.; CAVALCANTE, A. V.; ANDRADE, L. S.; WANDERLEY, C. R. P.; MARINHO, G.; PESSOA, K. A. R. Produção de ácido cítrico por Aspergillus niger AN 400 a partir de resíduo agroindustrial. Engenharia Sanitaria e Ambiental, 24.1: 101-107, 2019.

MAJOUGA, A.; SOKOLSKY-PAPKOV, M.; KUZNETSOV, A.; LEBEDEV, D.; EFREMOVA, M.; BELOGLAZKINA, E.; KLYACHKO, N . Enzyme-functionalized goldcoated magnetite nanoparticles as novel hybrid nanomaterials: synthesis, purification and control of enzyme function by low-frequency magnetic field. Colloids and Surfaces B: Biointerfaces, 125: 104-109, 2015.

MAJOUGA, A.; SOKOLSKY-PAPKOV, M.; KUZNETSOV, A.; LEBEDEV, D.; EFREMOVA, M.; BELOGLAZKINA, E.; KLYACHKO, N. Enzyme-functionalized goldcoated magnetite nanoparticles as novel hybrid nanomaterials: synthesis, purification and control of enzyme function by low-frequency magnetic field. Colloids and Surfaces B: Biointerfaces, 125, 104-109, 2015.

MENDES, K. D. S.; SILVEIRA, R. C. de C. P.; GALVAO, C. M. Revisão integrativa: método de pesquisa para a incorporação de evidências na saúde e na enfermagem. Texto \& contexto enfermagem, Florianópolis , v. 17, n. 4, dez. 2008. 
NELSON, D. L.; COX, M. M. Princípios de Bioquímica de Lehninger-7. Artmed Editora, 2018.

PRANDO, L. T.; MELCHIORS, M. S; TORRES, T. M. S.; OLIVEIRA, V. A.; VENERAL, J. G.; CASTIANI, M. A.; LUCCIO, M . Effect of high pressure and magnetic field treatments on stability of Candida antarctica lipase B (CALB) and lysozyme from chicken egg. Catalysis Communications, 116: 43-47, 2018.

PRANDO, LT.; LIMA, PR.; REZZADORI, K.; OLIVEIRA, JVD.; LUCCIO, M. Caracterização do desempenho e da atividade catalítica da lisozima de ovo de galinha submetido a campo magnético permanente. Industrial \& Engineering Chemistry Research, 56 (32), 9065-9071. 2017.

QUEIROZ, C.; SOUSA, A. C. B. Produção de enzimas hidrolíticas por fungos filamentosos em diferentes substratos sólidos. Brazilian Journal of Development, 6.7: 51849-51860, 2020 .

RIBEIRO, R. P. Enzimas lignocelulolíticas da microbiota ruminal de ovinos Morada Nova e seu potencial na sacarificação do bagaço de cana-de-açúcar. Embrapa Caprinos e Ovinos-Tese/dissertação (ALICE), 2019.

SAlES, F. H. S.; LOPES, J. T.; COSTA, I. S.; SANTOS, D. G.; PADILHA, L. L . A Influência do Campo Magnético na Germinação e no Crescimento de Vegetais. Revista Pindorama, 1.01: 15-15, 2018.

SILKSTONE, G.; WILSON, M. T. Uma investigação adicional dos efeitos de campos magnéticos de frequência extremamente baixa na fosfatase alcalina e acetilcolinesterase. Plos one, 11.3: e0148369, 2016. 